\title{
THROMBOCYTOPENIA; FREQUENCY AND ASSOCIATION AT THE TIME OF DIAGNOSIS IN DENGUE FEVER, PESHAWAR
}

Nauman Wazir ${ }^{1}$, Ayesha Malook ${ }^{2}$, Shafaq Naz ${ }^{3}$, Mohammad Arshad ${ }^{4}$, Shafqat ur Rehman $^{5}$, Adnan Mumtaz ${ }^{6}$

\section{ABSTRACT:}

OBJECTIVES: To determine the frequency of thrombocytopenia in dengue fever at the time of diagnosis and to see its association with age and gender.

METHODOLOGY: It was a descriptive retrospective study of dengue cases admitted to the Medical Unit of Naseer Teaching Hospital Peshawar during the 2019 outbreak was performed. Only confirmed dengue by serology (IgM) or dengue NS1 (Non-Specific Antigen 1) by Immunochromatographic Technique (ICT) cases were analysed. Complete Blood Count (CBC) was done for all the cases on admission and prevalence of thrombocytopenia on admission was extracted from the records. SPSS version 23 was used to analyse the data and to calculate Odds Ratio of a gender or age group to have thrombocytopenia at the presentation of dengue fever.

RESULTS: A total of 69 confirmed dengue cases were admitted in Naseer Teaching Hospital in the 2019 outbreak. Out of these 69 cases, 51 (73.9\%) were males and 18 (26.1\%) were females. The ages of these patients ranged from 1058 years. Fifty-one (51) patients were more than 20 years of age and eighteen (18) were 20 years or less. Thrombocytopenia (platelet count $<150,000 \times 10^{9} / \mathrm{L}$ ) was present in 57 (82.6\%) patients. Patients older than 20 years of age were more likely to have thrombocytopenia at presentation of dengue fever $O R=16$, $(p=0.0003)$, whereas difference amongst genders in this regard was not statistically significant $O R=1.07,(p=0.09)$.

CONCLUSION: There is a high frequency of thrombocytopenia (82.6\%) in early dengue fever. Patients older than 20 years are more likely to have thrombocytopenia in early dengue fever.

KEYWORDS: Dengue Fever, Acute Febrile IIIness, Thrombocytopenia

How to cite this article:

Wazir N, Malook A, Naz S, Arshad M, Rehman S, Mumtaz A. Thrombocytopenia; frequency and association at the time of diagnosis in dengue fever, Peshawar. J Gandhara Med Dent Sci. 2020;6(2):10-15. doi: 10.37762/jgmds.6-2.93 


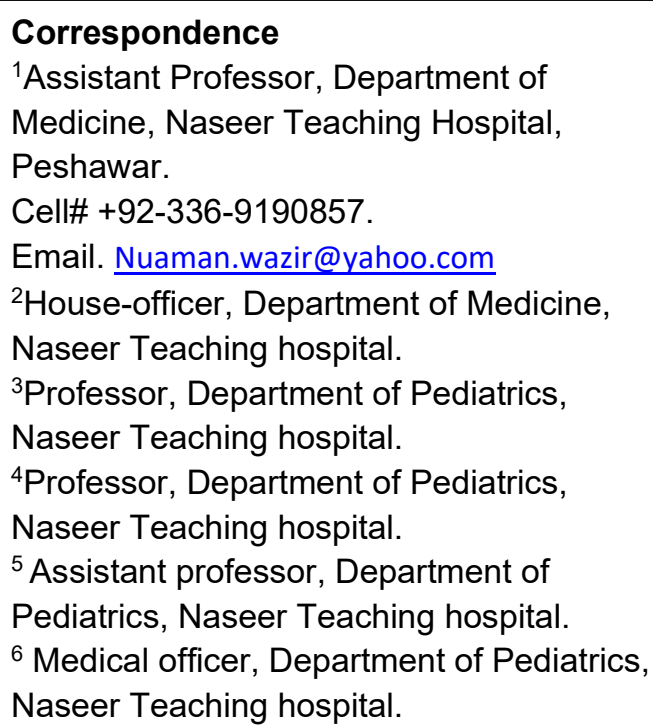

${ }^{1}$ Assistant Professor, Department of Medicine, Naseer Teaching Hospital, Peshawar.

Cell\# +92-336-9190857.

Email. Nuaman.wazir@yahoo.com

${ }^{2}$ House-officer, Department of Medicine,

Naseer Teaching hospital.

${ }^{3}$ Professor, Department of Pediatrics,

Naseer Teaching hospital.

${ }^{4}$ Professor, Department of Pediatrics,

Naseer Teaching hospital.

${ }^{5}$ Assistant professor, Department of

Pediatrics, Naseer Teaching hospital.

${ }^{6}$ Medical officer, Department of Pediatrics,

Naseer Teaching hospital.

\section{INTRODUCTION:}

Dengue is an arthropod-borne infectious disease caused by a Flavin virus, the dengue virus (DENV). Generally, dengue is a self-limiting acute febrile illness that is followed later by a phase of critical effervescence, characterized by either improvement or progression to a severe form. The features of severe illness are increased vascular permeability, hemodynamic compromise, intravascular volume depletion, hypotension, and shock. Thrombocytopenia is common in both the cases and is related to the clinical outcome. There are different mechanisms postulated to explain DENV-associated thrombocytopenia. They include bone marrow suppression and the peripheral destruction of platelets. Previous studies have shown that early in the dengue fever, there is bone marrow hypocellularity and slowing of megakaryocyte maturation ${ }^{1,} 2$. The mechanisms causing DENV-induced bone marrow suppression in the acute phase are not clear. However, there three main pointing suggestions: (1) direct toxic effects on progenitor cells by DENV; infection of stromal cells; (3) alterations in bone marrow regulation ${ }^{3}$. Thrombocytopenia in dengue fever may also be due to increased peripheral destruction by mechanisms suggested to be (1) platelet consumption in the coagulopathy process; complement system activation ${ }^{4}$; or (3) augmented peripheral sequestration ${ }^{5}$, 6 . A study by Tomashek et al, have found that even early in the clinical course of an acute febrile illness (AFI), thrombocytopenia is predictive of dengue across all age groups along with the fact that thrombocytopenia, as a predictor of dengue fever, strengthened over time $^{7}$. A study from Karachi, Pakistan has shown that thrombocytopenia was present in $100 \%$ patients with early suspected dengue fever ${ }^{8}$. Another study from Lahore, Pakistan showed that using the logistic regression model, platelet count showed statistically significant predictability of dengue haemorrhagic fever ${ }^{9}$. The northern part of Pakistan including Peshawar has been struck with deadly dengue outbreaks in this decade. Complete Blood Count (CBC) is a very cheap baseline test and thrombocytopenia in AFI could therefore give a clue towards its aetiology. We wanted to find out the frequency of thrombocytopenia in early confirmed dengue fever in a teaching hospital in Peshawar, 
Pakistan to emphasize the fact that thrombocytopenia early in the course of $\mathrm{AFI}$, utilizing a very cost-effective test (CBC), could be a pointer towards its cause in our region as well. To our knowledge, no local study has tried to find out the association of thrombocytopenia in early dengue fever with age and gender. Through this study, we also investigated this issue to find out specific populations where thrombocytopenia early in AFI could be a strong predictor of dengue fever.

\section{METHODOLOGY:}

It was an observational study where retrospective analysis was done for all cases that were admitted with the confirmed diagnosis (NS1 or IgM positive cases) of dengue fever during the outbreak of 2019 (September $1^{\text {st }}$ to November $20^{\text {th }}$ ) in Peshawar. Complete blood count including red cell count, haemoglobin, haematocrit, mean corpuscular volume, mean corpuscular haemoglobin concentration, platelets count, total leukocyte count, and differential leukocyte count of all the patients was performed at the time of diagnosis using automated haematology analyser of the hospital laboratory. Thrombocytopenia was defined as platelet count less than $150 \times 10^{\%} / \mathrm{L}$. Data was analysed using SPSS software version 23. Frequencies and percentage were used for qualitative variables like gender and thrombocytopenia. Mean \pm Standard Deviation was calculated for quantitative or numerical variables like age and platelet count at presentation. Patients younger than 20 years of age were grouped in young age group while those older than 20 years were classified as older age group. Odds ratio (OR) was calculated for association of gender and age groups with thrombocytopenia at the time of diagnosis of dengue fever.

\section{RESULTS:}

The demographic and laboratory variables of $n=69$ confirmed cases of dengue fever admitted to Naseer Teaching Hospital, Peshawar from $1^{\text {st }}$ September to $20^{\text {th }}$ November 2019, are shown in Table 1.

Table 1: Demographic \& Laboratory Characteristics of Confirmed Dengue Fever Patients

\begin{tabular}{|l|c|}
\hline \multicolumn{1}{|c|}{ Parameters } & Mean \pm SD, Number and Percentage \\
\hline Age & $31.30 \pm 12.38$ years \\
\hline Gender & $51(73.9 \%)$ \\
\hline Male & $18(26.1 \%)$ \\
\hline Female & $116 \pm 65.4 \times 10^{9} / \mathrm{L}$ \\
\hline Platelet count & \\
\hline Thrombocytopenia & $57(82.6 \%)$ \\
\hline Present & $12(17.4 \%)$ \\
\hline Not Present &
\end{tabular}

*SD=Standard Deviation 
All the cases were confirmed dengue fever. Sixty-nine (69) patients were positive for NS1 Dengue antigen and 3 were negative, which were positive for IgM Anti Dengue Antibody. The patients' age ranged from 10 years to 58 years. Platelet count ranged from 30 to $308 \times 10^{9} / \mathrm{L}$. Number of patients in different age categories and the presence or absence of thrombocytopenia in them is depicted in Figure 1. Patients older than 20 years of age were more likely to have thrombocytopenia at presentation of dengue fever $O R=16, \quad(p=0.0003)$. Female patients in early dengue fever had slightly more but statistically nonsignificant likelihood to have thrombocytopenia at presentation of dengue fever $\mathrm{OR}=1.07,(p=0.09)$.

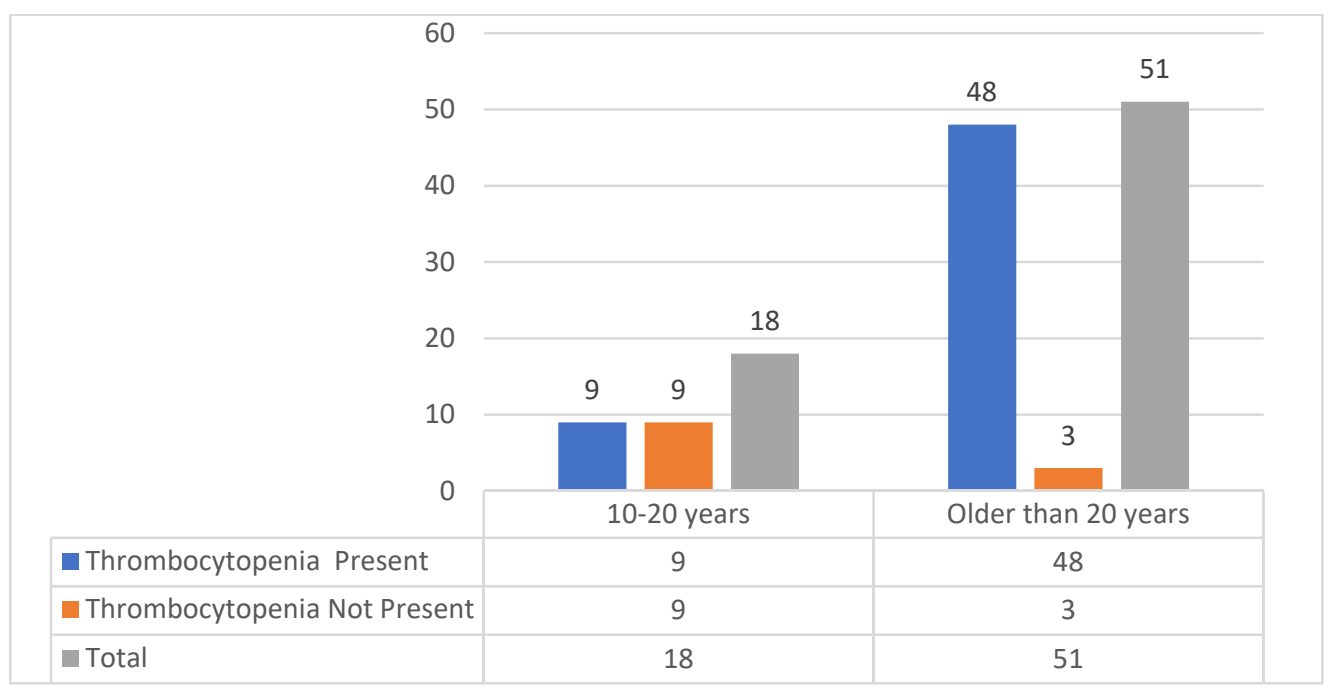

Figure 1: Thrombocytopenia as Diagnosis of Dengue Fever in Two Age Categories

\section{DISCUSSION:}

Dengue fever has now become endemic to Pakistan with outbreaks usually reported in every summer over the last decade. It is associated with considerable morbidity and mortality ${ }^{10}$. Thrombocytopenia is quite common in dengue fever ${ }^{11,12}$, and can give a clue towards the aetiology of acute febrile illness. In this study we tried to find out the frequency of thrombocytopenia in early dengue fever. In our study males dominated as a gender having dengue fever. Such a finding is also present in other national and international studies ${ }^{7,13-15}$.
Our study showed quite a high frequency of thrombocytopenia i.e. $82.6 \%$ right at the time of diagnosis of dengue fever. This finding is quite in line with a study from Saudi Arabia ${ }^{16}$, which found out the frequency of thrombocytopenia to be $79.49 \%$ amongst 80 patients who were admitted with suspicion of dengue fever, which was later, confirmed by serology. Similarly, in a local study from Punjab ${ }^{17}$, a retrospective analysis of 68 proven dengue fever found out the frequency of thrombocytopenia to be $88.8 \%$. In other local studies, the frequency of thrombocytopenia is even higher such 
as $90 \%^{11}, 95 \%^{12}$, and even $100 \%^{8}$. On the other hand, other studies have reported the prevalence of thrombocytopenia to be lower than ours; $60 \%{ }^{16}$ and $70 \%{ }^{17}$. However, thrombocytopenia has been demonstrated to be a positive factor for dengue fever early in the course of acute febrile illness in numerous international and national studies ${ }^{7-9}$. Mean platelet count in our study was $116 \pm 65.4 \times 10^{9} / \mathrm{L}$ (Mean $\pm \mathrm{SD}$ ). It is near to the one found in a Puerto Rican study ${ }^{7}$, where it was shown to be $121 \times 10^{9} / \mathrm{L}$. Mean platelet count in early dengue fever in another local study from Peshawar has been demonstrated to be $69.29 \pm 50.82 \times 10^{9} / \mathrm{L},{ }^{15}$ quite lower than found in ours. We also tried to find out association of gender or age with the presence of thrombocytopenia in early dengue fever. Patients older than 20 years of age were slightly more likely to have thrombocytopenia in early dengue fever in our study $(\mathrm{OR}=16)$. Older age ( $>55$ years) has been shown to be a predictor of mortality in dengue fever in a Brazilian study ${ }^{18}$. However, in contradiction to our study, an Argentinean study ${ }^{19}$, showed low platelets count in dengue fever to be associated with younger age. This is probably related to the fact that this study investigated a much younger (paediatric) age group as well, which we did not. The same study showed female gender to be predictor to worse clinical outcomes.

\section{CONCLUSION:}

There is a high prevalence of thrombocytopenia (82.6\%) in early dengue fever. Therefore, a simple test like CBC can be used as a possible screening test for dengue fever in acute febrile illness. Patients older than 20 years of age are more likely to have thrombocytopenia in early dengue fever.

\section{REFERENCES:}

1. Srichaikul $T$, Nimmannitya $S$. Haematology in dengue and dengue haemorrhagic fever. Bailliere's Best Prac Res Clin Haematol. 2000;13(2):261-76.

2. Kho LK, Wulur H, Himawan T. Blood and bone marrow changes in dengue haemorrhagic fever. Paediatr Indones. 1972;12(1):31-9.

3. Srichaikul T. Disseminated intravascular coagulation in dengue haemorrhagic fever. Southeast Asian $J$ Trop Med Public Health. 1987;18(3):303-11.

4. Krishnamurti C, Peat RA, Cutting MA, Rothwell SW. Platelet adhesion to dengue-2 virus-infected endothelial cells. Am J Trop Med Hyg. 2002;66(4):435-41.

5. Mitrakul C. Bleeding problem in dengue haemorrhagic fever: platelets and coagulation changes. Southeast Asian J Trop Med Public Health. 1987;18(3):407-12.

6. Srichaikul $T$, Nimmannitya $S$, Sripaisarn T, Kamolsilpa M, Pulgate C. Platelet function during the acute phase of dengue hemorrhagic fever. Southeast Asian J Trop Med Public Health. 1989;20(1):19-25.

7. Tomashek KM, Lorenzi OD, AndújarPérez DA, Torres-Velásquez BC, Hunsperger EA, Munoz-Jordan $\mathrm{JL}$, et al. Clinical and epidemiologic characteristics of dengue and other etiologic agents among patients with acute febrile illness, Puerto Rico, 
2012-2015. PLoS Negl Trop Dis. 2017;11(9): e0005859.

8. Butt N, Abbassi A, Munir SM, Ahmad SM, Sheikh QH. Haematological and biochemical indicators for the early diagnosis of dengue viral infection. $J$ Coll Physicians Surg Pak. 2008;18(5):282-5.

9. Ahmed S, Mohammad WW, Hamid F, Akhter A, Afzal RK, Mahmood A. The 2011 dengue haemorrhagic fever outbreak in Lahore-an account of clinical parameters and pattern of haemorrhagic complications. J Coll Physicians Surg Pak. 2013;23(7):463-7.

10. Kumar A, Rao CR, Pandit V, Shetty $\mathrm{S}$, Bammigatti $\mathrm{C}$, Samarasinghe CM. Clinical manifestations and trend of dengue cases admitted in a tertiary care hospital, Udupi district, Karnataka. Indian J Community Med. 2010;35(3):386-90.

11. Khan $A H$, Hayat AS, Masood N, Solangi NM, Shaikh TZ. Frequency and clinical presentation of dengue fever at tertiary care hospital of Hyderabad/Jamshoro. J Liaquat Uni Med Health Sci. 2010;9(2):88-94.

12. Butt MRA, Shahzad M, Iqbal A, Semaab. Dengue fever outbreak 2010: clinical experience in a teaching hospital of Lahore Pakistan. Pak J Med Health Sci. 2011;5(2):265-9.

13. Riaz MM, Mumtaz K, Khan MS, Patel J, Tariq M, Hilal $\mathrm{H}$, et al. Outbreak of dengue fever in Karachi

\section{CONTRIBUTORS}

1. Nauman Wazir - Concept \& Design; Data Analysis/Interpretation; Drafting Manuscript

2. Ayesha Malook - Data Acquisition

3. Shafaq Naz - Critical Revision; Supervision

4. Mohammad Arshad - Critical Revision

5. Shafqat ur Rehman - Critical Revision

6. Adnan Mumtaz - Data Acquisition
2006: a clinical perspective. J Pak Med Assoc. 2009;59(6):339-44.

14. Lodhi Y, Farooqi MM. Clinical characteristics of dengue fever in a medical center of Lahore during 2010 epidemics. Pak J Med Health Sci. 2012;6(1):129-31.

15. Ahmed F, Ali ZA, Hussain Z. Clinical and hematological profile of patients with dengue fever. J Med Sci. 2014;22(1):17-20.

16. Ayyub M, Khazindar AM, Lubbad $\mathrm{EH}$, Barlas S, Alfi AY, Al-Ukayli S. Characteristics of dengue fever in a large public hospital, Jeddah, Saudi Arabia. J Ayub Med Coll Abbottabad. 2006;18(2):9-13.

17. Khan HMS, uz-Zaman Q, Khan BA, Arif M, Raza A, Haq A. Retrospective analysis of 68 cases of dengue fever. Pak J Med Res. 2012;51(1):18-20.

8. Pinto RC, de Castro DB, de Albuquerque BC, de Souza Sampaio $V$, dos Passos RA, da Costa CF, et al. Mortality predictors in patients with severe dengue in the state of Amazonas, Brazil. PLoS One. 2016;11(8):e0161884.

19. Byrne AB, Gutierrez GF, Bruno A, Córdoba MT, Bono MM, Polack FP, et al. Age-associated differences in clinical manifestations and laboratory parameters during a dengue virus type 4 outbreak in Argentina. J Med Virol. 2018;90(2):197-203. 